\title{
ALGUMAS NOTAS SOBRE IMAGEM E PALAVRA NA ARTE DA MEMÓRIA
}

\author{
AngÉlica Chiappetta* \\ Universidade de São Paulo
}

Resumo. O texto relembra a técnica de "lugares" e "imagens" para a Arte da Memória, apresentada em vários tratados de Retórica. As referências passeiam de Cícero e Quintiliano até uma Arte Memorativa do séc. XVII. A construção de lugares mnemônicos e de palácios da memória é comentada, sugerindo a relevância da imagem para a construção do pensamento.

Palavras-chave. Memória; arte da memória; palácio da memória; arte retórica; Cícero. D.O.I. 10.11606/issn.2358-3150.v19i1p54-68

No seu “Arte da Memória”, Francis YATes fala de UMA TRAdição CiCERoniana da técnica de memorização que teria preservado os mesmos preceitos da arte de memorizar desde a Antiguidade até, pelo menos, o séc. $18 .{ }^{1}$ Nessa tradição, o material a ser memorizado é traduzido em imagens que são ordenadas na mente em lugares previamente escolhidos e organizados. Isso faz com que as artes da memória que seguem tal tradição sejam um material interessante para estudar, nos contextos que as utilizam, as relações entre imagem e palavra, operando como que uma espécie de inverso da ékphrasis.

Falando das partes da Retórica, Cícero trata a Memória como fundamento, guardiã e tesouro do discurso:

Quid dicam de thesauro rerum omnium, memoria? Quae nisi custos inuentis cogitatisque rebus et uerbis adhibeatur, intellegimus omnia, etiam si praeclarissima fuerint in oratore, peritura. ${ }^{2}$

Que direi da memória, tesouro de todas as coisas? A menos que ela tenha sido empregada como guardiã das coisas e palavras encontradas e pensadas, entendemos que todas, mesmo se tiverem estado muitíssimo claras no orador, se perderão.

\footnotetext{
• Doutora em Letras Clássicas pela Universidade de São Paulo (1997).

*Artigo recebido em 05.ago.2015 e aceito para publicação em 31.out.2015.

${ }^{1}$ Estas notas tomam como referência as discussões apresentados em dois outros textos que estão no prelo: A. Chiappeta. "Cícero e a tradição ciceroniana da arte da memória" (no prelo); e A. Chiappeta. "Uma Arte da Memória do séc. XVII" (no prelo).

${ }^{2}$ Cic., De Or. 1.18.
} 
Sed earum omnium rerum ut aedificiorum memoria est quasi fundamentum, lumen actio. ${ }^{3}$

Mas a memória, como acontece com os edifícios, é por assim dizer o fundamento de todas as coisas; a ação é a luz.

Mary Carruthers, no seu The Book of Memory, esclarece que a memória não deve ser entendida como um substituto da escrita num mundo eminentemente oral. ${ }^{4}$ Memória e cultura escrita não se excluem, como mostra a aproximação entre as duas presente nas Partições Oratórias e tantas vezes repetida:

(memoria est) gemina litteraturae quodammodo et in dissimili genere persimilis. Nam ut illa constat ex notis litterarum et ex eo in quo imprimuntur illae notae, sic confectio memoriae tamquam cera locis utitur et in his imagines ut litteras collocat."

(a memória é) de certa maneira, gêmea da escrita e muito semelhante de um modo diferente. Pois como a escrita consta de anotações das letras e daquilo em que se imprimem tais anotações, assim a composição da memória usa os lugares como cera e neles coloca imagens como se fossem letras.

Séculos depois de Cícero, em 1627, o jesuíta Cristóvão Bruno retoma a mesma tradição e inicia sua Arte da Memória assim:

Memória, como definem os filósofos, é uma potência da alma que esconde e guarda, como em depósito, as espécies e imagens de todas as cousas que conhecemos para as manifestar quando for necessário. Esta ou é natural ou artificial. Para conservar e acrescentar aquela se dão muitos e mui excelentes remédios que aqui não aponto porque é meu intento tratar somente da artificial. Artificial se adquire com uso dos preceitos que neste tratado apontaremos. E geralmente falando, como os livros constam de papel ou pergaminho e de letras expressas nele, assim a memória artificial consta de lugares, como de carta, e de imagens, como de letras. Os lugares ou são naturais e verdadeiros ou fingidos e imaginados. As imagens, também, ou são naturais e próprias do que queremos representar, ou tais que tenham semelhança e proporção com a cousa de que nos queremos lembrar. ${ }^{6}$

O estudo da Memória começa por dividi-la entre memória natural e memória artificial. A arte, neste como em qualquer caso, pode aprimorar a natureza.

Na passagem do De oratore $^{7}$ em que se refere à memória artificial, Cícero diz que demorar-se explicitando os preceitos da arte, inventada por Simônides e tão conhecida de todos, seria prolixo e redundante.

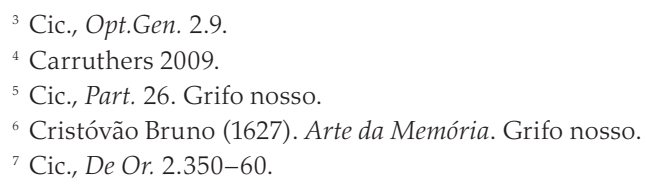


Qua re ne in re nota et peruulgata multus et insolens sim, locis est utendum multis, inlustribus, explicatis, modicis interuallis; imaginibus autem agentibus, acribus, insignitis, quae occurrere celeriterque percutere animum possint."

Por isso (para que num assunto tão conhecido e divulgado eu não seja prolixo e redundante) devem-se usar muitos lugares, bem iluminados, desobstruídos, com módicos intervalos. E imagens que agem, vivas, notáveis, que rapidamente possam se apresentar e tocar o ânimo.

É de se supor que o treinamento nessa técnica fazia parte da instrução elementar e era bastante difundido entre gregos e romanos. Assim, Cícero rapidamente lembra apenas que o material a ser usado pelo artista da memória são os lugares e as imagens: para memorizar algo é preciso transformá-lo em imagens mentais e colocar as imagens formadas em lugares mentais previamente ordenados.

Quanto aos lugares, diz que devem ser muitos e bem iluminados, desobstruídos, regularmente distribuídos; as imagens devem ser "imagines agentes". A técnica funciona porque as coisas percebidas pelos sentidos são guardadas no nosso ânimo com o auxílio da visão:

Verum tamen neque tam acri memoria fere quisquam est, ut, non dispositis notatisque rebus, ordinem uerborum omnium aut sententiarum complectatur, neque uero tam hebeti, ut nihil hac consuetudine et exercitatione adiuuetur. Vidit enim hoc prudenter siue Simonides siue alius quis inuenit, ea maxime animis effingi nostris, quae essent a sensu tradita atque impressa; acerrimum autem ex omnibus nostris sensibus esse sensum uidendi; qua re facillime animo teneri posse ea, quae perciperentur auribus aut cogitatione, si etiam commendatione oculorum animis traderentur. ${ }^{9}$

Certamente, não há quase ninguém que possua memória tão aguçada a ponto de abarcar a ordem de todas as palavras e sentenças estando as coisas não organizadas e marcadas; por outro lado, ninguém tem memória tão debilitada que em nada possa ser ajudado por este hábito e exercício. Com efeito, Simônides, ou outro que tenha inventado (a arte da memória) percebeu isto com sagacidade: as coisas que são melhor retratadas (effingi) no nosso ânimo são aquelas trazidas e impressas pelos sentidos; e entre todos os nossos sentidos o sentido da visão é o mais aguçado; razão pela qual podem ser facilmente conservadas em nosso ânimo coisas recebidas pelos ouvidos ou pelo pensamento se forem levadas aos ânimos com a recomendação dos olhos.

\section{Quintiliano apresenta o procedimento dizendo:}

Primum sensum vestibulo quasi adsignant, secundum (puta) atrio, tum inpluvia circumeunt, nec cubiculis modo aut exhedris, sed statuis etiam similibusque per ordinem committunt. Hoc facto, cum est repetenda memoria, incipiunt ab initio loca haec

\footnotetext{
${ }^{8}$ Cic., De Or. 2.358. Grifo nosso.

${ }^{9}$ Cic., De Or. 2.357-8. Grifo nosso.
} 
recensere, et quod cuique crediderunt reposcunt, ut eorum imagine admonentur. Ita, quamlibet multa sint quorum meminisse oporteat, fiunt singula conexa quodam choro, nec onerant coniungentes prioribus consequentia solo ediscendi labore. ${ }^{10}$

O primeiro pensamento é colocado, por assim dizer no átrio; o segundo, digamos, no salão de entrada: os demais são dispostos na ordem adequada em torno do impluvium e confiados, não simplesmente aos dormitórios e salas de visitas, mas também ao encargo das estátuas e similares. Feito isso, quando a memória for solicitada, percorre-se, começando do início, todos esses lugares e retoma-se aquilo que a cada um foi confiado, na medida em que se faz lembrar pela sua imagem. Dessa forma, não importa a quantidade de coisas que se deve lembrar: elas estarão ligadas umas às outras como em uma coreografia e não pode haver erro uma vez que ligam o que se segue ao que veio antes sem outro trabalho senão a tarefa preliminar de memorização.

A fonte do que está guardado na memória pode ser bastante diversa, mas tudo o que chega ao ânimo está aí transformado numa imagem que pode ser vista e explorada pelo "olho da mente". A fluência de quem tem uma memória treinada pela técnica dos lugares e imagens é a mesma do bailarino que executa uma coreografia harmoniosamente ensaiada; não há engano ou hesitação sobre qual é o próximo passo. E é por isto, diz Quintiliano, que merecidamente a memória é chamada de tesouro da eloquência, "nec inmerito thesaurus hic eloquentiae dicitur". Ela serve de suporte a todas as atividades necessárias ao orador:

Sed non firme tantum continere verum etiam cito percipere multa acturos oportet, nec quae scripseris modo iterata lectione complecti, sed in cogitatis quoque rerum ac verborum contextum sequi, et quae sint ab adversa parte dicta meminisse, nec utique eo quo dicta sunt ordine refutare sed oportunis locis ponere. ${ }^{11}$

Ela não deve apenas reter com firmeza, mas também resgatar rapidamente o que vai ser dito em seguido; e não somente guardar, por meio de repetidas leituras, o que se escreveu há pouco, como também seguir o conjunto das palavras e das coisas no pensamento; e as coisas ditas pela parte contrária deve recordar não para refutá-las na ordem exata em que foram ditas, mas para apresentá-las num momento apropriado.

O que se está chamando de memória é aqui uma "habilidade" em guardar com firmeza o material do discurso e retomar com agilidade o que está guardado quando se está prestes a falar. A memória treinada serve, portanto, para estocar um discurso previamente preparado por escrito e, também, para no curso do pensamento, escolher do material previamente ordenado o que pode ser usado no discurso que se está fazendo de improviso. "Quin extemporalis oratio non alio mihi videtur mentis vigore cons-

\footnotetext{
${ }^{10}$ Quint., Inst. 9.2.20.

${ }^{11}$ Quint., Inst. 9. 2.2.
}

Let. Cláss., São Paulo, v. 19, n. 1, p. 54-68, 2015 
tare", "não em outro vigor mental parece-me apoiar-se um discurso improvisado", diz Quintiliano. ${ }^{12}$ A memória serve, ainda, para ouvir o discurso alheio de maneira ordenada, de modo a reter, no caso do embate judiciário, por exemplo, o que poder ser usado numa contra-argumentação. Quem domina a técnica pode falar com segurança e "in longissimis actionibus prius audiendi patientia quam memoriae fides deficit", "num discurso muito longo, a paciência dos ouvintes termina antes da fidelidade da memória".13

Quando perguntada, o que invariavelmente aconteceu, se a arte da memória que estudava de fato funciona, Mary Carruthers respondia que sim, desde que usada para os fins a que se presta, ou seja, como um instrumento do pensar. Afirmava que na retórica a tarefa da memória é, acima de tudo, cumprir uma etapa da composição do discurso; retomar o que está na memória é uma ato de investigação e recriação de um artífice consciente. ${ }^{14}$

Desde a Retórica a Herênio a memória artificial é dividida em memoria rerum e memoria verborum, memória de coisas e memória de palavras. ${ }^{15}$ Ali o autor dá um exemplo de como seria a memória de coisas; diz com frequência reter todo o assunto de um caso numa única imagem. Por exemplo, um acusador declara ter um homem morrido por envenenamento e argumenta que o fato se deu por causa de uma herança, e ainda informa haver muitas testemunhas e pessoas cientes disso. Para esse caso conceberia a imagem do homem em questão, doente na cama, se o conhecesse; caso contrário, tomaria algum outro doente, desde que não fosse de origem humilde, para que pudesse vir rápido à mente; instalaria o acusado ao lado de sua cama, segurando na mão direita um copo (para lembrar o envenenamento), na esquerda uma tabuinhas (para a herança), no anular, testículos de carneiro (para as testemunhas, aqui para semelhança sonora entre testis (testemunha) e testiculi (testículos).

Para a memória de palavras, o exemplo é o caso em que se queira memorizar palavra por palavra o seguinte verso:

Iam domum itionem reges Atridae parant

Os reis Atridas já preparam o caminho para casa

No primeiro lugar de memória coloco Domício (Domitium) elevando as mãos para o céu enquanto é açoitado pelos reis Márcios (domum itionem). As figuras da cena são personagens ilustres, para ajudar na retenção da imagem. Num segundo lugar, Esopo e Cimber (dois famosos atores de teatro) se aprontando para encenar Ifigênia, como Agamenão e Menelau (atridae parant).

${ }^{12}$ Quint., Inst. 11.2.3.

${ }^{13}$ Quint., Inst. 11.2.8.

${ }^{14}$ Carruthers 2009, X.

${ }^{15}$ Her. 3.28-40. 
As artes da memória gregas estão perdidas para nós, mas o autor do Ad Herennium faz menção a elas, inclusive para criticar seu suposto procedimento de padronizar as imagens a serem utilizadas:

Scio plerosque Graecos, qui de memoria sripserunt, fecisse, ut multorum verborum imagines conscriberent, uti, qui ediscere vellent, paratas haberent, ne quid in quaerendo consumerent operae. Quorum rationem aliquot de causis inprobamus: primum, quod in verborum innumerabili multitudine ridiculumst mille verborum imagines conparare. (...) Praeterea similitudine alia alius magis commovetur. Nam ut saepe, formam si quam similem cuipiam dixerimus esse, non omnes habemus adsensores, quod alii videtur aliud, item fit $<$ in $>$ imaginibus, ut, quae nobis diligenter notata sit, ea parum videatur insignis aliis. ${ }^{16}$

Sei que a maioria dos gregos que escreveram sobre a memória o fizeram listando imagens de muitas palavras, para que as tivessem prontas aqueles que quisessem sabê-las de cor, e para que não consumissem esforços procurando-as. Desaprovo o método deles por algumas razões: primeiro, porque em meio a uma inumerável quantidade de palavras, é ridículo selecionar imagens para milhares delas. (...) Além disso, alguém se impressiona mais com uma semelhança do que com outra. Como ocorre muitas vezes, quando digo que uma figura é semelhante a outra, de não ter a aprovação de todos (pois cada um vê de maneira diferente), o mesmo acontece com as imagens: o que para mim está cuidadosamente marcado, para outros parecerá pouco destacado.

Que não se critique, portanto, a pertinência das imagens utilizadas como exemplo para a memória de coisas e para e memória de palavras; elas devem ser escolhidas de maneira a se fixarem o melhor possível na mente do memorizador e esse processo é individual, cada um deve escolher o que é efetivo para si.

Carruthers chama a atenção para o equívoco de se restringir o entendimento da expressão memoria verborum ou memoria sententiarum como memorização palavra por palavra de textos longos. ${ }^{17}$ Segundo a autora, o método aqui serve mais como instrumento de retomada do que de retenção; depois de dividir e ordenar o material, serve-se do dispositivo para encontrar o material guardado. Para se memorizar um discurso já pronto, é preciso primeiro dividi-lo em partes:

Quando ergo vis operari cum ymaginibus sentenciarum, tunc non est averte necesse singulas dictiones ex quibus illa sententia componitur, sed comprehendere bene eius substanciam facti et reducere illam in summam et secundum hanc formare ymaginem. ${ }^{18}$

\footnotetext{
${ }^{16}$ Her., 3.38-9.

${ }^{17}$ Carruthers 2009, XII.

${ }^{18}$ Ars memorativa (1425), 3.1.
} 
Quando queres operar com imagens de sentenças, não é necessário tomar cada uma das expressões das quais aquela sentença se compõe, mas compreender bem a substância daquele feito, reduzi-la ao máximo e formar uma imagem de acordo com ela.

Leremos, pois, a pregação e o mesmo se entende na lição, oração, poema ou em qualquer outra cousa que quisermos estudar por esta memória, e notaremos todos os passos dela atentamente os quais iremos repartindo com sua ordem pelos lugares acima ditos, da mesma maneira que fizemos na primeira e segunda memória (ou seja, memória das coisas materiais e das imateriais). Com esta diferença somente, que ali púnhamos um só nome em cada lugar, aqui poremos a substância de um passo inteiro ou parte dela, procurando que o homem que estiver no tal lugar me exprima o passo com algum gesto ou meneio, para o que servirá muito o uso e exercício da segunda memória e ter facilidade em representar e materializar as cousas imateriais e incorpóreas. ${ }^{19}$

Por exemplo, imagine-se uma pregação dividida em cem passos. Cristóvão Bruno ensina a escolher cem lugares de memória, colocar neles cem homens e entregar a cada um dos homens uma imagem para o início do passos que se quer lembrar:

Depois de repartir os passos e conceitos da pregação pelos ditos homens da maneira que temos dito, trataremos do princípio dos [f.150] períodos, membros ou partes da oração, os quais também se hão de pôr nos mesmos lugares e pela mesma ordem dos passos, fazendo que o primeiro homem, a quem tenho dado o primeiro passo, me exprima também o princípio ou primeira palavra do primeiro período. O segundo homem me represente o segundo período ou segunda parte da oração, representando-me e materializando-me a primeira palavra dela. E assim em todos os mais, de sorte que quem me exprimir o passo, me represente também o princípio do período em que ele está, porque isto basta para excitar a memória natural, que logo se vai lembrando de tudo o que se tem estudado, como poderá experimentar quem guardar pontualmente todas as advertências acima ditas. ${ }^{20}$

Se o material estiver bem ordenado nos lugares de memória, a imagem de cada lugar servirá para lembrar de algo que, por sua vez, excitará a memória natural. Ou seja, para lembrar de um período com a memória de palavras, não é preciso necessariamente compor imagens palavras por palavras, mas, antes, ordenar bem e seguramente algumas imagens que estimulem a memória natural. Com isso, a técnica se assemelha a um processo de estocagem do material do discurso em lugares ordenados e posterior manuseio do que foi estocado. Algo que se poderia chamar de um tópica; o que, por sua vez, mostra a proximidade da memória com a invenção retó-

\footnotetext{
${ }^{19}$ Cristóvão Bruno (1627). Grifo nosso.

${ }^{20}$ Cristóvão Bruno (1627). Arte da Memória. Grifo nosso.
} 
rica. Na sua Topica Aristóteles já faz menção a isso, comparando os lugares da argumentação com os lugares mnemônicos. ${ }^{21}$

Uma Ars Memorativa de 1425, anônima, esclarece que, na verdade, tanto as imagens como os lugares de memória são imagens mentais:

Loca non differunt ab ymaginibus nisi in hoc, quia loca non sunt anguli, ut quidam putant, sed ymagines fixe cum toto situ circumstante, supra quas, sicut supra cartam, alie pinguntur ymagines delebiles, sicut littere super carta. Unde loca sunt sicut materia, ymagines vero sicut forma, differunt ergo eciam sicut fixum et non fixum. ${ }^{22}$

Os lugares não diferem das imagens senão nisto, que os lugares não são cantos, como alguns pensam, mas imagens fixas com toda sua posição conservada, sobre as quais, como sobre papel, outras imagens deléveis são pintadas, como letras sobre papel. De onde os lugares são como a matéria, e as imagens como a forma, diferem também como fixo e não fixo.

\section{Cristóvão Bruno, em 1627, ensina a construir um conjunto de lugares de memória:}

Primeiramente se há de escolher uma casa grande ou uns como paços não fingidos e imaginados, como os que diremos abaixo, mas reais e verdadeiros, nos quais não more atualmente quem os escolhe, porque a experiência nos tem mostrado que a memória se confunde grandemente com os lugares em que atualmente moramos. Será, porém, tal esta casa que quem a escolher, ou por ter antes morado nela ou entrado muitas vezes, esteja mui bem visto em todos cantos e lugares dela.

Nesta casa pois, por espaço de dois ou três dias, se hão de notar com muita quietação e sossego todos os lugares principais e mais insignes, como são porta, escada, janela, escritório, armários, livraria, cama, cozinha e outros semelhantes, correndo-os com a imaginação como se os estivesse vendo com os olhos. E, para o poder fazer mais facilmente e com maior perfeição, imaginarei que os estou mostrando a algum amigo por esta ordem.

Entrarei com ele pela porta da casa, ou por qualquer outro lugar que me parecer mais acomodado para o meu intento, e continuando sempre à mão direita ir-lhe-ei mostrando todos os lugares da casa os mais notáveis e insignes, guardando pontualmente todas as advertências seguintes. (...)

Escolhidos pois, e determinados estes lugares, são necessários dois ou três dias mais para os correr mui devagar, não já como quem os vai repetindo, mas como quem adverte e conta todas as miudezas e particularidades deles, porque este exercício ajuda grandemente para com facilidade e sem reflexão alguma os poder depois repetir e correr com a imaginação. (...)

O que agora se segue parecerá a alguém supérfluo e ridículo; contudo, a experiência mostrará quanto serve para nosso intento e achará que é uma das mais proveitosas e importantes advertências que aqui se põem.

${ }^{21}$ Arist., Top. 8,14, 163b: "Como o sistema de lugares (tópoi) é útil na mnemônica, assim, na argumentação, alguém se torna melhor disposto se tiver lançado na memória premissas de ocorrência mais frequente e de aplicação geral", apud Caplan 1970, 228.

${ }^{22}$ Ars Memorativa (1425), 2.1. Grifo nosso. 
São pois necessários cinco dias pelo menos para neles fazer exercício em fingir a tudo o que vir com os olhos movimento que provoque o riso, temor ou espanto e digo que quanto com a maior destreza se fingirem estes movimentos tanto mais facilmente se poderá usar, não só desta, mas de todas as mais memórias de que trataremos adiante. ${ }^{23}$

Com isso teremos uma casa com cem lugares para colocarmos cem imagens correspondentes a uma lista de cem coisas (nomes, objetos, coisas imateriais etc) que queiramos guardar. Na mesma Arte, Cristóvão Bruno ensina como construir um palácio de memória de 1536 lugares, útil não quando queremos guardar uma lista, mas quando precisamos memorizar um longo texto. Ele terá quatro andares, com quatro corredores e quatro salas em cada corredor. Para que a regularidades dos corredores e das portas das salas não nos confunda, é preciso distinguir as salas. As imagens sugeridas para tanto hoje soam um tanto bizarras:

Ponhamos exemplo. No primeiro corredor da primeira quadra estarão os quatro quartos de um homem; a cabeça ensangüentada estará sobre a primeira porta do primeiro cubículo deste corredor. Os braços estarão sobre a primeira porta do quarto cubículo, tudo ensangüentado para despertar mais a memória. No segundo corredor desta primeira quadra, pode estar um boi repartido em quartos pelos quatro cubículos. No terceiro, um leão esquartejado. No quarto, um cavalo da mesma maneira repartido e despedaçado. Esta ordem e distinção se guardará nas portas e cubículos dos outros andares, para o que cada um poderá escolher os animais que lhe parecerem mais acomodados para os distinguir uns dos outros e excitar a memória, em que sempre se hão de ter os olhos. ${ }^{24}$

Cícero, no De oratore, diz não concordar com os que criticam a mnemônica e seu uso das imagens alegando que todo esse material assim disposto pode atulhar a mente e causar mais dano que benefício:

Neque verum est, quod ab inertibus dicitur, opprimi memoriam imaginum pondere et obscurari etiam id, quod per se natura tenere potuisset: vidi enim ego summos homines et divina prope memoria, Athenis Charmadam, in Asia, quem vivere hodie aiunt, Scepsium Metrodorum, quorum uterque tamquam litteris in cera, sic se aiebat imaginibus in eis locis, quos haberet, quae meminisse vellet, perscribere. Qua re hac exercitatione non eruenda memoria est, si est nulla naturalis; sed certe, si latet, evocanda est. ${ }^{25}$

E não é certo o que dizem os não peritos, que a memória pode ver-se oprimida pelo peso das associações e que, inclusive pode obscurecer-se o que a natureza por si mesma teria podido reter, pois eu conheci homens ilustres e de memória quase divina, em Atenas Cármadas e, na Ásia, Metrodoro de Escepsis, que dizem que ainda vive, dos quais um e outro diziam que, assim como as letras numa tabuinha de cera, do mesmo modo podiam descrever com detalhe - mediante as imagens que tinham nos lugares

${ }^{23}$ Cristóvão Bruno (1627). Arte da Memória.

${ }^{24}$ Cristóvão Bruno (1627). Arte da Memória.

${ }^{25}$ Cic., De Or. 2.360.

Let. Cláss., São Paulo, v.19, n.1, p.54-68, 2015 
- o que queriam recordar. Por isso como tal exercício não se pode arruinar a memória se naturalmente é nula; mas, se está latente, pode-se despertá-la.

Novamente nesse trecho aparece a aproximação da técnica dos lugares e das imagens com a escrita, paralelo já mencionado por Aristóteles no De anima: "É possível, com efeito, criar ficções (na alma) e contemplá-las como fazem os que ordenam as idéias, segundo a técnica mnemônica, criando imagens". ${ }^{26}$ Igualmente interessante é a aproximação que se pode fazer com a pintura:

(Imaginatio) Quasi optimus pictor hausta rerum sensilium simulachra, suo penicillo memoriae designat. ${ }^{27}$

(A imaginação) Acolhe os simulacros das coisas sensíveis e, ao modo de um excelente pintor, os marca com seu pincel na memória.

Neque ulla ars vel scientia est que magis artificiali memoria sit conformis quam pictori: proprie et ipsa locis et ymaginibus indiget sicut et ista, et una alteram multum insequitur, ideo ad illam artem de pingendi quandoque pro exemplis occurrere est satis utile: depingimus et nos cum figuramus ymagines in locis. ${ }^{28}$

Não há arte ou ciência que seja mais conforme à memória artificial do que a do pintor: propriamente, tanto aquela como essa precisam de imagens e lugares e uma segue muito de perto a outra, pelo que resulta muito útil tirar exemplos algumas vezes daquela arte de pintar: também nós pintamos quando figuramos imagens nos lugares.

A memória pode ser vista como uma pintura mental onde estão figuradas a invenção e disposição e a elocução do discurso. É preciso aprender a pintar imagens convenientes para a função, imagens que fiquem impregnadas na mente e facilitem a memorização. A excessiva familiaridade, por exemplo, pode fazer com que a imagem seja delével; assim, o exagero, o grotesco, o ridículo, o pouco usual são elementos importantes para uma imagem mnemônica:

Imagines sunt rerum aut verborum similitudines in mente conceptae. Duplices autem similitudunes esse debent, ut ait Cicero, una rerum, alia verborum. Rerum autem similitudinem constituuntur cum summatim ipsorum negotiorum imagines comparamus, verborum autem similitudines exprimuntur cum uniuscuiusque vocabuli memoria a nobis imagine notatur (...) Et premicto pro generali regula imaginum collocandarum

${ }^{26}$ Arist., De An. 427b, 18-22.

${ }^{27}$ Della Porta (1558). Ars reminiscendi, apud Bolzoni 2007, 284.

${ }^{28}$ Giovanni Fontana (1430). Secretum de thesauro experimentorum ymaginationis hominum, apud Bolzoni 2007, 245. 
quod in locis semper collocandae sunt imagines cum motu et acto ridiculoso crudeli admirativo aut turpi vel impossibili sive alio insuteo. ${ }^{29}$

Imagens são similitudes concebidas na mente de coisas e de palavras. E essas similitudes devem ser de dois tipos, como diz Cícero, uma de coisas, outra de palavras. As similitudes de coisas são formadas quando compomos resumidamente imagens dos próprios assuntos; similitudes de palavras são expressas quando a memória de cada vocábulo é assinalada por nós (...) E antecipo como regra geral da colocação de imagens que nos lugares sempre devem ser colocadas imagens com movimento e ato ridículo, cruel, admirável ou torpe ou impossível ou outro não habitual.

Si igitur daretur tibi ad memorandum nomes proprium, puta Petrus vel Martinus, debes accipere aliquem Petrum tibi notum ratione amicitiae vel inimicitiae, virtutis vel vituperri vel precellentis pulcritudinis aut nimiae deformitatis, non ociosum sed se exercitatem motu aliquo ridiculoso." ${ }^{30}$

Assim, se te for dado para memorizar um nome próprio, como Pedro ou Martinho, deves tomar algum Pedro teu conhecido por motivo de amizade ou inimizade, virtude ou vitupério, elevada beleza ou demasiada feiúra, não parado, mas se mexendo com algum movimento ridículo.

Se eu quero me lembrar de um enamorado, não imaginarei a pessoa do lugar bem vestida e arrumada, suspirando e fazendo outras coisas convenientes a um cavalheiro enamorado, mas a pintarei como Ovídio descreve a Polifemo apaixonado, arrumando a barba com a foice e penteando o cabelo com a rastelo, enquanto se olha na água como em um espelho, e tocando e cantando com um instrumento musical esquisito. Porque, sendo tão ridícula a imagem, despertará a lembrança mais facilmente em minha memória. ${ }^{31}$

A técnica da memória é descrita como pintura das coisas que se quer memorizar. Uma lista de nomes, requer imagens de pessoas para cada nome; o mesmo para uma lista de coisas materiais. Mas, como acontece com os mudos, que se comunicam com os gestos, a pintura e a memória também podem formar imagens em que os gestos farão o papel de elementos associativos:

Unde cum nil aliud sit haec ars, quam memorandarum rerum picturam memoriae explicare et quomodo egregius pictor alicuius rei cuius imaginem ignorat, poterit in pictura repraesentare? $?^{32}$

Dado que esta arte não é outra coisa senão expor à memória a pintura das coisas que devem ser memorizadas, de que modo um egrégio pintor poderá representar na pintura alguma coisa cuja imagem ignora?

\footnotetext{
${ }^{29}$ Tractatus solemnis artis memorativae (1434), apud Rossi 2004, 368. Grifo nosso.

${ }^{30}$ Tractatus solemnis artis memorativae (1434), apud Rossi 2004, 368. Grifo nosso.

${ }^{31}$ Della Porta (1558). Ars Reminiscendi, apud Bolzoni 2007, 202. Grifo nosso.

${ }^{32}$ Della Porta (1558). Ars Reminiscendi apud Bolzoni 2007, 285. Grifo nosso.
} 
Pictura tacens opus est habitus semper eiusdem, sic gestus intimos affectus exprimit, ut ipsam vim dicendi nonnunquam superare videatur. In mutis pro sermone sunt gestus et manu et nutu suua voluntatem declarant. animalium quoue sermone carentium, ira, laetitia, adulatio, oculis et quibusdam aliis corporis signis deprehenditur" ${ }^{33}$

A pintura é obra silenciosa e mostra sempre a mesma atitude, o gesto exprime os afetos íntimos de modo que muitas vezes parece superar a força do dizer. Nos mudos, em lugar do discurso estão os gestos e com a mão e o movimento declaram sua vontade; a ira, a alegria e a adulação dos animais que carecem de discurso são depreendidas pelos olhos e outros sinais do corpo.

Segundo a técnica, pode-se transformar em imagem mesmo as coisas não materiais, lembrando, por exemplo, que os movimentos, atos e gestos do corpo podem ser significativos: "Per motus corporis et actus ymagines formantur", "As imagens se podem formar usando os movimentos e os atos do corpo" [Ars memorativa (1425)]. Cristóvão Bruno fala em " dar com a imaginação corpo proporcionado a todas as cousas imateriais" [Arte da Memória (1627)]. É possível representar uma coisa por seu efeito, como a alvura pela neve ou cisne, quentura pelo fogo ou febre, doçura pelo mel. Os afetos da alma podem ser representantes por pessoas insignes, como a ira por Aquiles. Podem, também, ser representados por gestos e partes do corpo: cabeça levantada - soberba, baixa - tristeza, olhos caídos - vergonha, abrasados - ira, nariz levantado - riso, o peito coberto - engano, aberto - sinceridade, coração - amor, fel - ira, mãos caídas - dor ou desesperação, juntas e levantadas - rogos e oração, apertadas diante dos ombros - admiração, abertas e estendidas - liberalidade, apertadas avareza, a direita levantada sobre o ombro - ameaça, apertado o punho levantada denota - fortaleza, ombros - paciência, dedo na boca - silêncio, língua - o contrário. E, ainda, podem os afetos da alma ser representados por animais: ira - leão, simplicidade - pomba, prudência - serpente, sagacidade - raposa, inocência - cordeiro. Essa associações, no entanto, devem ser tomadas apenas se forem impressionantes para o memorizar. O melhor é exercitar-se na capacidade própria de formar imagens impressionantes para si, como já dizia o autor Ad Herennium.

Agostinho descreve belamente o percurso pela paisagem mental da memória:

Et venio in campos et lata praetoria memoriae, ubi sunt thesauri innumerabilium imaginum de cuiuscemodi rebus sensis invectarum. ibi reconditum est quidquid etiam cogitamus, vel augendo vel minuendo vel utcumque variando ea quae sensus attigerit,

${ }^{33}$ Della Porta (1558). Ars reminiscendi, "Quomodo ex gestu recordari possumus", apud Bolzoni 2007, 222. 
et si quid aliud commendatum et repositum est quod nondum absorbuit et sepelivit oblivio. Ibi quando sum, posco ut proferatur quidquid volo, et quaedam statim prodeunt, quaedam requiruntur diutius et tamquam de abstrusioribus quibusdam receptaculis eruuntur, quaedam catervatim se proruunt et, dum aliud petitur et quaeritur, prosiliunt in medium quasi dicentia, "ne forte nos sumus?" et abigo ea manu cordis a facie recordationis meae, donec enubiletur quod volo atque in conspectum prodeat ex abditis. alia faciliter atque imperturbata serie sicut poscuntur suggeruntur, et cedunt praecedentia consequentibus et cedendo conduntur, iterum cum voluero processura. quod totum fit cum aliquid narro memoriter. ${ }^{34}$

E chego aos campos e vastos palácios da memória onde estão tesouros de inumeráveis imagens trazidas por percepções de toda espécie. Aí está também escondido tudo o que pensamos, quer aumentando quer diminuindo ou até variando de qualquer modo os objetos que os sentidos atingiram. Enfim, jaz aí tudo o que se lhes entregou e depôs, se é que o esquecimento ainda o não absorveu e sepultou. Quando lá entro mando comparecer diante de mim todas as imagens que quero. Umas apresentam-se imediatamente, outras fazem-me esperar por mais tempo, até serem extraídas, por assim dizer, de certos receptáculos ainda mais recônditos. Outras irrompem aos turbilhões e, enquanto se pede e se procura uma outra, saltam para o meio, como que a dizerem: "Não seremos nós?" Eu, então, com a mão do espírito, afasto-as do rosto da memória, até que se desanuvie o que quero e do seu esconderijo a imagem apareça à vista ("memória natural"). Outras imagens ocorrem-me com facilidade e em série ordenada, à medida que as chamo. Então as precedentes cedem lugar às seguintes, e, ao cedê-lo, escondem-se, para de novo avançarem quando eu quiser ("memória artificial"). É o que acontece quando digo alguma coisa de memória.

A memória é um palácio onde se guardam, em imagens, os tesouros trazidos pela percepção. Na memória natural, essas imagens correm os risco de estar desordenadas e, quando se deseja lembrar algo, fica-se a mercê de esperar que a coisa a ser lembrada se apresente diante dos "olhos da mente". Até que chegue a imagem correta, esses olhos são confundidos e distraídos por várias falsas semelhanças. Para uma memória treinada, no entanto, não há esse risco: as imagens ocorrem com facilidade, ordenadas e em série; apresentam-se uma a uma, sem hesitação, e cedem o lugar para a próxima sem atropelos.

Essa figuração da memória e do pensamento está presente em descrições que, em princípio, pouco têm a ver com as artes mnemônicas, como por exemplo a seguinte:

Suponhamos que eu tenha diante de mim um quebra-cabeça feito de figuras. Ele retrata uma casa com um barco no telhado, uma letra solta do alfabeto, a figura de um homem correndo, com a cabeça misteriosamente desaparecida, e assim por diante. Ora, eu poderia ser erroneamente levado a fazer objeções e declarar que o quadro como um todo, bem como suas partes integrantes, não fazem sentido. Um barco não

${ }^{34}$ August., Conf. 10.8.

Let. Cláss., São Paulo, v.19, n.1, p.54-68, 2015 
tem nada que estar no telhado de uma casa e um homem sem cabeça não pode correr. Ademais, o homem é maior do que a casa e, se o quadro inteiro pretende representar uma paisagem, as letras do alfabeto estão deslocadas nele, pois esses objetos não ocorrem na natureza. Obviamente, porém, só podemos fazer um juízo adequado do quebra-cabeça se pusermos de lado essas críticas da composição inteira e de suas partes, e se, em vez disso, tentarmos substituir cada elemento isolado por uma sílaba ou palavra que possa ser representada por aquele elemento de um modo ou de outro. As palavras assim compostas já não deixarão de fazer sentido, podendo formar uma frase poética de extrema beleza e significado. O sonho é um quebra-cabeça pictográfico desse tipo. ${ }^{35}$

Trata-se da descrição de Freud, no capítulo 6 da Interpretação dos Sonhos, para as imagens formadas no processo onírico. São imagens bizarras, confusas e até grotescas, cujo sentido escapa à primeira vista; assim como as imagens mnemônicas, não seguem a lógica das figurações coerentes. E assim como imagens mnemônicas, se lidas segundo as associações de quem as elaborou, revelam-se extremamente significativas e mesmo poéticas.

É bem comum que os manuais de memória artificial reservem algum espaço para a arte do esquecimento. Afinal, depois de construído, um palácio da memória pode ser usado para guardar, sucessivamente, diferentes materiais. Para cada lista de nomes, coisas, pedaços de um discurso, devese colocar as imagens correspondentes nos lugares do palácio. Quando se quer guardar uma nova lista, é preciso "apagar" as imagens e preservar os lugares que receberão a nova lista. Lambert Schenkel, no seu De memoria liber, de 1595, propõe oito procedimentos diferentes para apagar as imagens. Eles vão num crescendo de dificuldade e até mesmo de violência diante da insistência de certas imagens. Aqui vão o sétimo e o oitavo procedimentos recomendados pelo autor para se imaginar uma cena que leve ao apagamento/esquecimento das imagens:

Septimus omnia cubicula et castra scopis purgaverit, atque invisibiles sibi imagines deposuverit, aut propter preciositatem e loco moverit, ne pulvere maculenter. Octavus, fingimus furore percitum hominem, comitatum armata corona, castra, domos, cubicula occupasse, alias imagines occidisse; multa percississe, timore alias per ianuas fugisse, alias per fenestra se praecipitasse, ac intrantes nulla invenite. ${ }^{36}$

Sétimo: uma criada terá varrido todos os quartos ("do pálio da memória") e todo o alojamento e sendo as imagens invisíveis para ela, as terá jogado fora, ou as terá tirado do lugar por causa da sua preciosidade, para que não tomassem pó. Oitavo: imaginemos que um homem tomado de furor, acompanhado de um bando armado, tenha ocupado os alojamentos, as casas, os quartos e tenha matado algumas imagens, que tenha ferido muitas e que outras, por medo, fugiram pelas portas ou se atiraram pelas janelas, e vocês que entram (no lugar) nada encontrem.

\footnotetext{
${ }^{35}$ Freud 1996, 303-4.

${ }^{36}$ Lambert Schenkel (1595). De Memoria Liber apud Bolzoni 2007, 196.
} 
A memória treinada na arte dos lugares e imagens pode, literalmente, traduzir um discurso em uma espécie de teatro interior. Isso porque imagens e lugares da arte reproduzem na interioridade as paixões que as figuras criam na exterioridade da elocução. Ainda, essas mesmas técnicas regulam a invenção de novos discursos segundo o traçado e os tesouros dos palácios do pensamento. E quando, por fim, ouvimos um discurso alheio, é observando-lhe a arquitetura e a regularidade que julgamos de sua riqueza e adequação.

\section{REFERÊNCIAS}

Bolzoni, L. 2007. La estancia de la memória. Modelos literários e iconográficos en la época de la imprenta. Madrid: Cátedra.

Caplan, H. 1970. "Memoria: Treasure-House of Eloquence." In Of Eloquence. Studies in Ancient and Medieval Rhetoric. NewYork: Cornell University Press.

Carruthers, M. 2009. The Book of Memory. A Study of memory in Medieval Culture. Cambridge: Cambridge University Press.

Freud, S. 1996. A interpretação dos Sonhos, cap. vI: "O trabalho dos sonhos". Obras Completas, vol. IV. Rio de Janeiro: Imago.

Rossi, P. 2004. A Chave Universal. Artes da memorização e lógica combinatória desde Lúlio até Leibniz. Bauru: EDUSC.

Title. On images and words in the Art of Memory.

Abstract. The text recalls the technique of the loci and images of the Art of Memory, presented in various rhetoric treatises. The references range from Cicero and Quintilian to the Art of Memory from the XVII century. The construction of mnemonic loci and memory palaces are commented, suggesting the relevance of the image in the construction of thought.

Keywords. Memory; art of memory; memory palace; rhetoric art; Cicero. 